Article

\title{
Dust Characteristics Observed by Unmanned Aerial Vehicle over the Taklimakan Desert
}

\author{
Chenglong Zhou ${ }^{1,2,3}$, Yuzhi Liu ${ }^{2,3, *}$, Qing He ${ }^{1,4,5,6}$, Xinjie Zhong ${ }^{7}$, Qingzhe Zhu ${ }^{2,3}$, Fan Yang ${ }^{1,4,5,6}$, \\ Wen Huo 1,4,5,6 ${ }^{D}$, Ali Mamtimin 1,4,5,6 ${ }^{\mathbb{D}}$, Xinghua Yang ${ }^{8}$, Yu Wang ${ }^{1,4,5,6}$ and Lu Meng 1,4,5,6
}

1 Institute of Desert Meteorology, China Meteorological Administration, Urumqi 830002, China; zhoucl@idm.cn (C.Z.); qinghe@idm.cn (Q.H.); yangfan@idm.cn (F.Y.); huowenpet@idm.cn (W.H.); ali@idm.cn (A.M.); wangyu@idm.cn (Y.W.); menglu@idm.cn (L.M.)

2 Key Laboratory for Semi-Arid Climate Change of the Ministry of Education, College of Atmospheric Sciences, Lanzhou University, Lanzhou 730000, China; zhuqzh18@lzu.edu.cn

3 Collaborative Innovation Center for Western Ecological Safety, Lanzhou University, Lanzhou 730000, China

4 Taklimakan National Station of Observation and Research for Desert Meteorology in Xinjiang, Urumqi 830002, China

5 Taklimakan Desert Meteorology Field Experiment Station, China Meteorological Administration, Urumqi 830002, China

6 Xinjiang Key Laboratory of Desert Meteorology and Sandstorm, Urumqi 830002, China

7 Bayingol Mongolian Autonomous Prefecture Meteorological Administration, Korla 841000, China; zhouchl20@lzu.edu.cn

8 School of Geographical Sciences, Shanxi Normal University, Taiyuan 030000, China; yangxh@idm.cn

* Correspondence: liuyzh@lzu.edu.cn

check for updates

Citation: Zhou, C.; Liu, Y.; He, Q.; Zhong, X.; Zhu, Q.; Yang, F.; Huo, W.; Mamtimin, A.; Yang, X.; Wang, Y.; et al. Dust Characteristics Observed by Unmanned Aerial Vehicle over the Taklimakan Desert. Remote Sens. 2022, 14, 990. https://doi.org/10.3390/ rs14040990

Academic Editors: Ugo Cortesi and Arno Keppens

Received: 23 January 2022

Accepted: 15 February 2022

Published: 17 February 2022

Publisher's Note: MDPI stays neutral with regard to jurisdictional claims in published maps and institutional affiliations.

Copyright: () 2022 by the authors Licensee MDPI, Basel, Switzerland. This article is an open access article distributed under the terms and conditions of the Creative Commons Attribution (CC BY) license (https:// creativecommons.org/licenses/by/ $4.0 /)$.

\begin{abstract}
Based on observations from the Unmanned Aerial Vehicle (UAV) together with an environmental particulate matter analyzer (Grimm-180) and Global Positioning System (GPS) sounding balloons, the vertical structure of dust with different particle sizes was explored over the Taklimakan Desert (TD) during an intensive observation from 1 July 2021 to 31 July 2021. The power functions were fitted between the particle counts and particle sizes, indicating negative correlations with an $\mathrm{R}^{2}$ higher than 0.99 under different dust pollution conditions in Tazhong (TZ). The dust concentrations show a sharp vertical increase over the TD during dust pollution; however, more particles with larger sizes are entrained into the air in TZ compared with Minfeng (MF). The total solar radiation during dust pollution days is significantly weakened, accompanied by major modifications in the temperature stratification, which were characterized by low-level cooling (with $-2.71 \mathrm{~K}$ mean intensity) and high-level heating (with $+0.70 \mathrm{~K}$ mean intensity). On clear days, the average convective boundary layer (CBL) heights at the TZ and MF are approximately 3.94 and $2.84 \mathrm{~km}$, respectively, and the average stable boundary layer (SBL) height at the TZ and MF are approximately 0.19 and $0.14 \mathrm{~km}$, respectively. With the increasing dust pollution level, the CBL height decreases rapidly while the SBL height shows the opposite trend. The unique ultra-high atmospheric boundary layer structure in daytime provides beneficial conditions for the suspension and vertical transportation of dust over TD. Moreover, a negative correlation between the CBL height and near-surface $\mathrm{PM}_{10} / \mathrm{PM}_{2.5} / \mathrm{PM}_{1.0}$ concentration in TD is revealed by power function fittings.
\end{abstract}

Keywords: suspended dust; particulate matter concentration; atmospheric boundary layer; Taklimakan Desert

\section{Introduction}

Dust is one of the strongly light-absorbing aerosols, which directly absorbs and scatters solar radiation and indirectly alters cloud microphysical properties, resulting in the changing radiation budget of the land-atmosphere system and global/regional climate change [1-4]. The Taklimakan Desert (TD) is one of the largest shifting deserts in the world and is an important source of dust aerosols in Asia [5,6]. Moreover, TD dust has high 
absorptivity, optical properties, and more significant radiation forcing compared with other desert areas in the world [7]. Therefore, the study of TD dust plays an important role in global dust weather and the atmospheric environment.

The vertical distribution of dust aerosols is one of the important parameters in the estimation of the dust radiative effect [8,9]. Since the Cloud-Aerosol Lidar and Infrared Pathfinder Satellite Observations (CALIPSO) satellite was launched, the study in the vertical structure of dust aerosols under different spatiotemporal conditions had become possible [10,11]. For example, Huang et al. analyzed the distribution of different types of aerosols on a global scale from five years of CALIPSO data [12]. Guo et al. established 3D (three-dimensional) models of the occurrence frequency of smoke and dust aerosols in China based on multi-sourced satellite observation data (CALIPSO; OMI, Ozone Monitoring Instrument; and MODIS, Moderate Resolution Imaging Spectroradiometer) [13]. Liu et al. gained further insights into the generation, emission, transport, distribution, and speciation of aerosols over East Asia based on five years' worth of CALIPSO Level 3 data [14]. Although the vertical structure of dust can be obtained from the macro scale through CALIPSO data, the study of the vertical structure of dust with different particle sizes is still very limited.

In fact, among a series of parameters that are used to characterize aerosol properties, aerosol size distribution is of great significance in the estimation and prediction of the dust emission-transport-deposition processes and their influences on human health and climate change [15]. However, the size distribution of suspended dust always varies spatially and temporally, even in the same dust event [16]. At present, there has been a growing consensus that predicting the abundance of different sizes of dust particles for the global energy balance with reliable accuracy is very important [17-20]. Therefore, it is desirable to obtain the vertical structure of dust with different particle sizes.

In this study, a field experiment was initiated with an intensive observation period of one month in the summer at the Tazhong (TZ) and Minfeng (MF) stations, which are representatives of the hinterland and southern TD, respectively. Meteorological elements, $\mathrm{PM}_{10}$, $\mathrm{PM}_{2.5}$ and $\mathrm{PM}_{1.0}$ concentrations, radiative data, and high-resolution GPS sounding data were obtained. The objectives of this study were to: (1) obtain the grain size characteristics of the dust particles in the near-surface over TZ; (2) analyze the vertical structure of dust with different particle sizes; and (3) estimate the dust radiative forcing and atmospheric boundary layer (ABL) height over the TD.

\section{Materials and Methods}

\subsection{Experimental Station}

The dust weather mainly occurs in the hinterland and south of the TD, and it is concentrated in the spring and summer seasons. Zhou et al. found that the annual mean dust days of TZ and MF were more than 200 days according to ten years of meteorological data, indicating dust weather as their main weather phenomenon [6]. Therefore, an intensive field experiment was conducted from 1 July to 31 July 2021 at the TZ and MF experimental stations, Xinjiang Province, China (Figure 1). The geomorphology of the TZ area is dominated by sand dunes [21]; MF is in the convergence and rising area of the TD wind field [22]. TZ and MF are categorized as the national reference climate station. We obtained the daily averaged data of air temperature, wind speed, and atmospheric pressure in this study. These observation items are detailed in Table 1.

Table 1. Meteorological observation at TZ and MF.

\begin{tabular}{cccc}
\hline Observation Item & Sensor Type & Measuring Height & Acquisition Frequency \\
\hline Air temperature & PT100 & $1.5 \mathrm{~m}$ & $0.5 \mathrm{~Hz}$ \\
Wind speed & EL15-1C & $10 \mathrm{~m}$ & $4 \mathrm{~Hz}$ \\
Atmospheric pressure & HYPTB210 & $1.2 \mathrm{~m}$ & $0.5 \mathrm{~Hz}$ \\
\hline
\end{tabular}




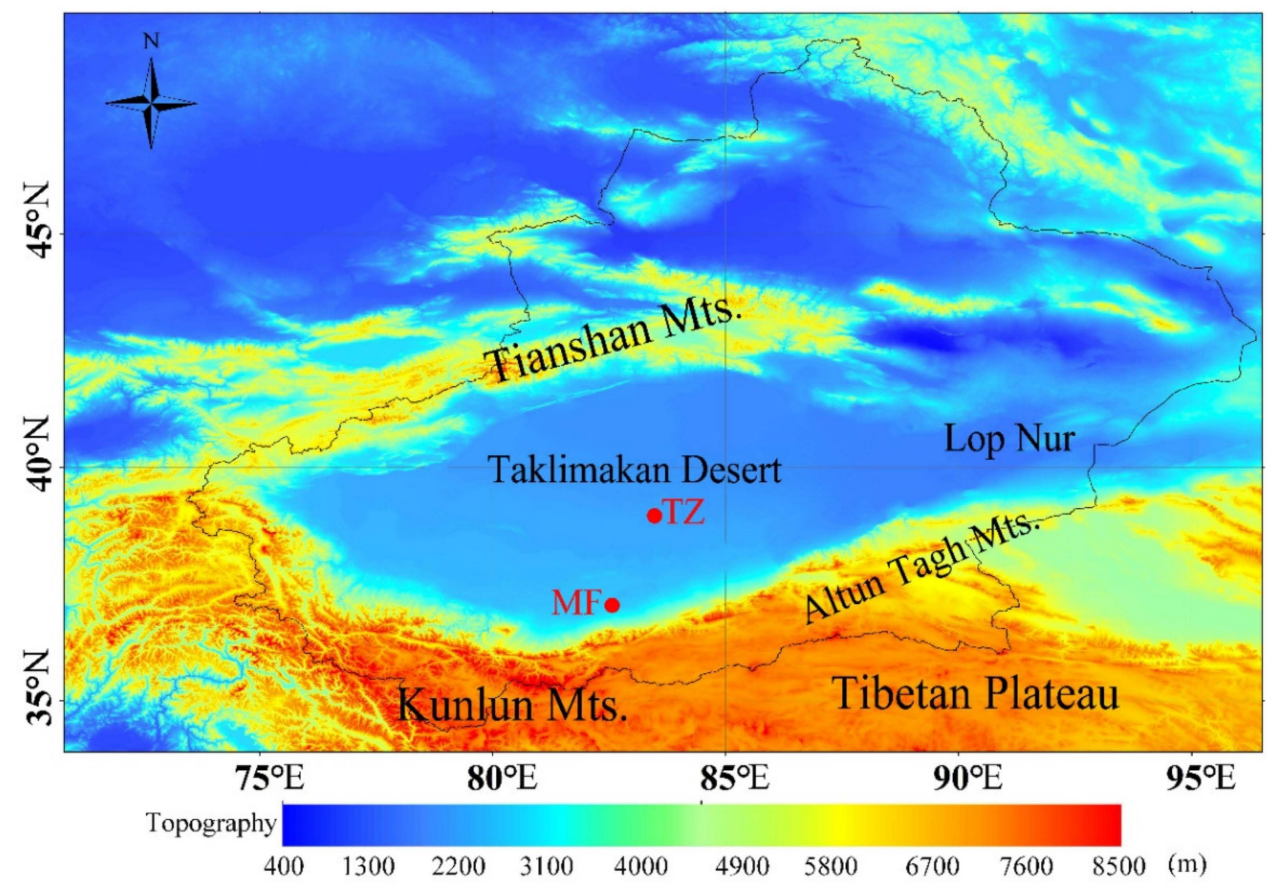

Figure 1. Topographical map of this study domain, observation sites highlighted in red solid circles, namely TZ and MF.

\subsection{Unmanned Aerial Vehicle (UAV)}

The UAV is provided by Hangzhou Zog communication equipment Co., Ltd, which supports the measurement of the $\mathrm{PM}_{1.0}, \mathrm{PM}_{2.5}$, and $\mathrm{PM}_{10}$ concentrations, meteorological elements, radiation, and other factors. The overall design of the UAV integrates the stringent requirements of ergonomics and aviation meteorology, and adopts the concept of modular, solid-state, and digital sensors, which can quickly measure atmospheric compositions and meteorological parameters. On the data analysis platform, the atmospheric 3D state is calculated and displayed in combination with the horizontal and vertical data distribution obtained by the GPS and terrain. The UAV models are UAV4000 and UAV6000 in TZ and MF, respectively. The only difference between them is that UAV4000 supports the observation of total solar radiation. The UAV experiment was conducted from 24 July to 31 July 2021, which was carried out every $3 \mathrm{~h}$ in Beijing time (UTC + 8; similarly, hereinafter): 08:00, 11:00, 14:00, 17:00, 20:00, 23:00, and 02:00. Due to the height limit of the airspace, the maximum flight altitude is $1 \mathrm{~km}$ in MF and $2 \mathrm{~km}$ in TZ. We carried out quality control on the original UAV data and eliminated outliers with a resolution of $5 \mathrm{~m}$.

\subsection{Grimm-180}

The environmental particulate matter analyzer selected for this field experiment is made in Germany (Grimm-180). Grimm-180 can simultaneously obtain the PM mass concentration $\left(\mathrm{PM}_{1.0}, \mathrm{PM}_{2.5}\right.$, and $\left.\mathrm{PM}_{10}\right)$ in the ambient atmosphere based on the principle of laser scattering, which complies with European standards EN $12341\left(\mathrm{PM}_{10}\right)$ and EN14907 $\left(\mathrm{PM}_{2.5}\right)$ and obtained American EPA certification $\left(\mathrm{PM}_{2.5}\right)$. The equipment does not need consumables and will automatically prompt possible error status and required maintenance, thus it greatly improves the reliability of the system. Meanwhile, it can measure the particle size distribution data of 31 channels. The measurement range for the mass concentration is from 0.1 to $6000 \mu \mathrm{g} / \mathrm{m}^{3}$ and the particle concentration is from 1 to 2,000,000 $\mathrm{p} / \mathrm{L}$ with a time resolution of $6 \mathrm{~s}$.

\subsection{GPS Sounding Balloons}

The GPS radiosonde system used is developed by Beijing Changfeng Microelectronics Technology Co., Ltd. and mainly consists of a GPS radiosonde and ground antenna 
receiving system. The data acquisition frequency is $1 \mathrm{~Hz}$ and the average speed of the sounding balloon is $300 \mathrm{~m} / \mathrm{min}$. The main meteorological elements observed by the system include air temperature, air pressure, relative humidity, and wind speed/direction. The sounding observation was carried out every $6 \mathrm{~h}$ in Beijing time: 02:00, 08:00, 14:00, and 20:00. The profile data were averaged to a vertical resolution of $10 \mathrm{~m}$. In this study, we evaluated the ABL height according to the thermodynamic method as follows $[23,24]$ : the potential temperature was calculated based on the temperature profiles and the height, where there was a discontinuous gradient and strong inversion, was defined as the ABL height.

\section{Results}

\subsection{An Overview of Dust Pollution Based on Ground Observations}

Figure 2a,b illustrates the temporal variations of the surface meteorological elements during July 2021 in MF and TZ. When dust weather occurs, the temperature (T) drops rapidly from a relatively higher value; higher wind speed (WS) is recorded, with average WS of 1.87 and $3.07 \mathrm{~m} / \mathrm{s}$ on clear days and dusty days, respectively. However, the lower surface pressure $(\mathrm{P})$ is observed during dusty days $(865.6 \mathrm{hPa})$, while the average $\mathrm{P}$ during clear days is $867.2 \mathrm{hPa}$. This indicates that dust events occurred under favorable weather conditions, including high wind speed and temperature and low surface pressure, which are consistent with the previous study [25].

(a) MF
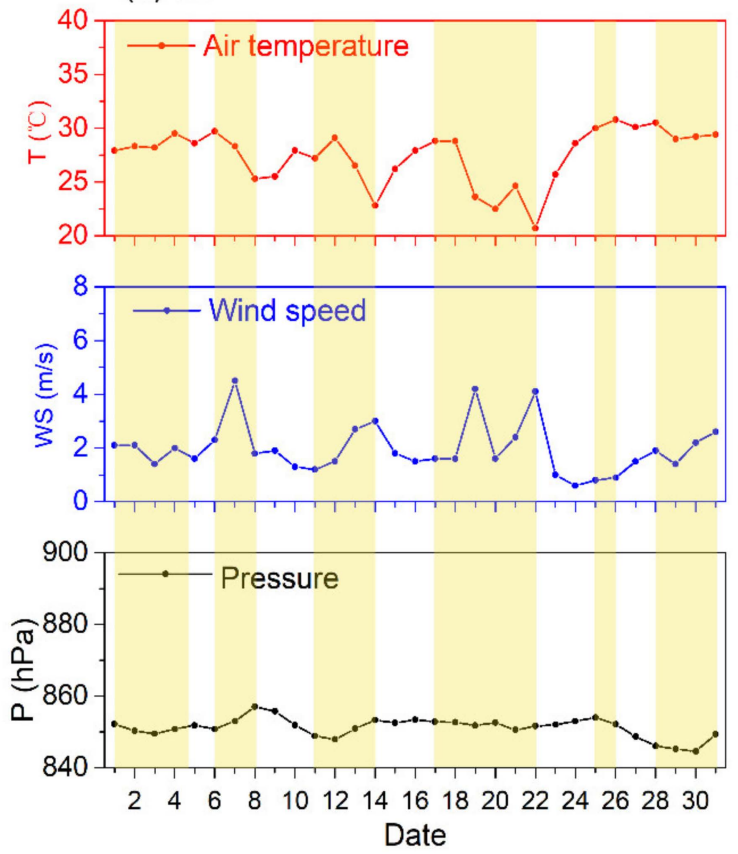

(b) TZ
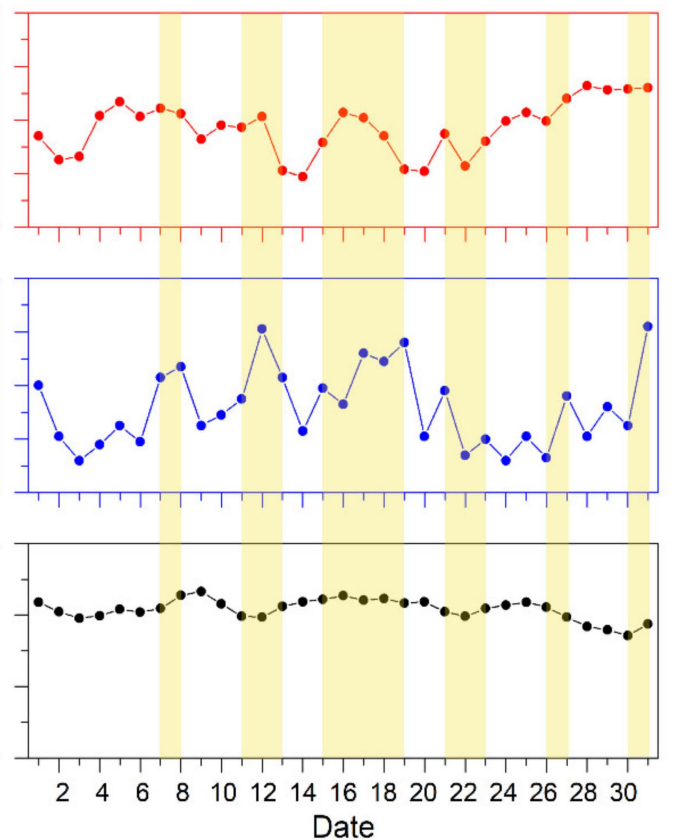

Figure 2. Temporal variations of temperature, wind speed, and surface pressure in the surface layer during July 2021 in MF (a) and TZ (b). The yellow shaded area represents the dust weather.

The grain size characteristics of the dust particles not only influence their accumulation and transport but also reveal the material composition of the sediments in the source area. Therefore, the analysis of grain size is a necessary link to dust emission [26-28]. Based on the National Environmental Protection Standards of China (HJ 633-2012), the ambient air quality can be divided into six grades (Table 2) [29]. 
Table 2. AQI index of different grades.

\begin{tabular}{ccccccc}
\hline Pollution Level & $\mathbf{1}$ & $\mathbf{2}$ & $\mathbf{3}$ & $\mathbf{4}$ & $\mathbf{6}$ \\
\hline AQI & $0-50$ & $51-100$ & $101-150$ & $151-200$ & $201-300$ \\
Air quality & excellent & good & light pollution & moderate pollution & heavy pollution & severe pollution \\
\hline
\end{tabular}

In this study, excellent and good air quality is defined as clear days, and heavy and severe pollution are combined and categorized into heavy pollution due to the limited number of samples. The grain size characteristics of dust particles under different nearsurface dust pollution levels during July 2021 in TZ are shown in Figure 3. The power functions were fitted between these two variables, indicating negative correlations with an $\mathrm{R}^{2}$ higher than 0.99 under different dust pollution conditions. The counts of particles increase rapidly with the aggravation of dust pollution; however, particle counts decrease at a slower rate under larger particle sizes. When the particle size is larger than $10 \mu \mathrm{m}$, the particle counts reduce to near-zero. Zhou et al. carried out a summer observation in MF based on a QCM cascade impactor, which found that the surface particles with sizes larger than $10 \mu \mathrm{m}$ are also almost undetectable on both clear days and dusty days [16]. Therefore, the dust particle size is mainly less than $10 \mu \mathrm{m}$ in MF and TZ. Generally, dust particles with less than $20 \mu \mathrm{m}\left(\mathrm{PM}_{20}\right)$ can suspend in the air and participate in global transport.

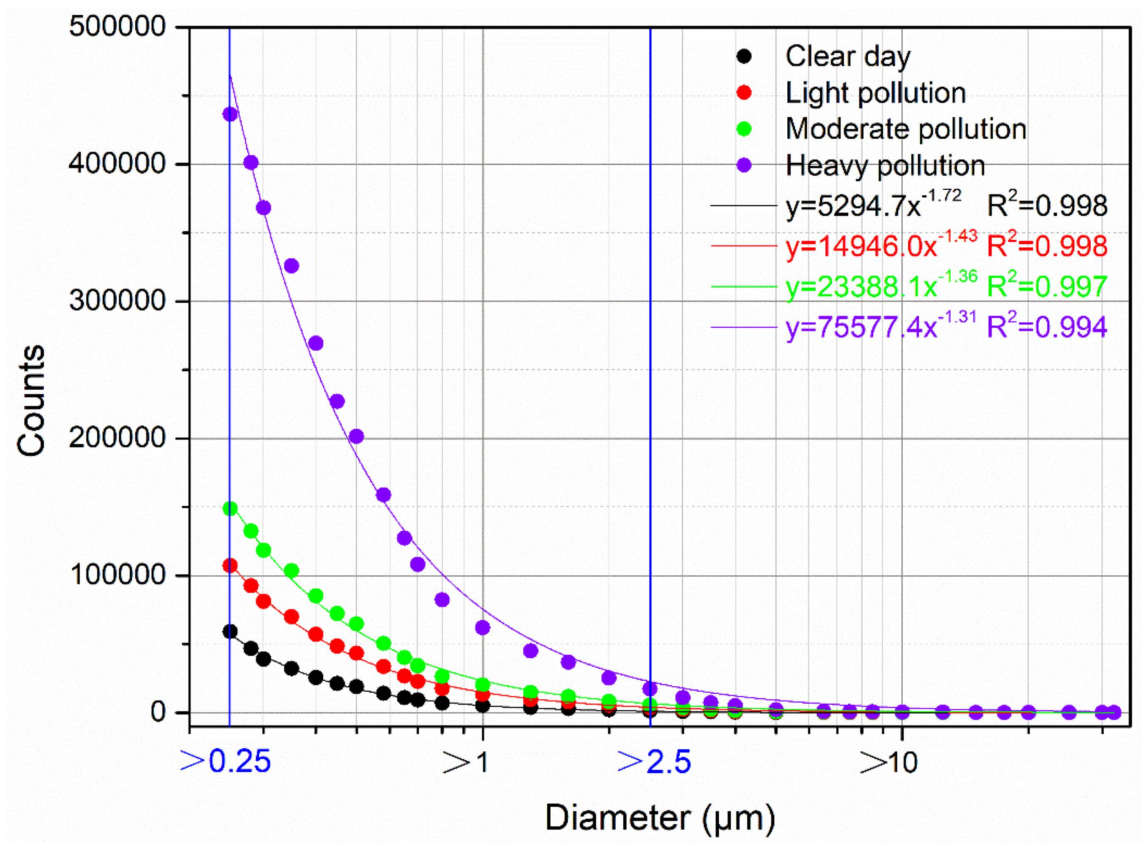

Figure 3. Distribution of surface particle size under different dust pollution levels near-surface in TZ during July 2021.

Figure 4 illustrates a comparison of the dust pollution level and near-surface concentration in MF and TZ during July 2021. Figure 4a shows that the clear days account for $86.2 \%$ in $\mathrm{TZ}$, while the air quality is worse in MF with only $54.8 \%$ clean weather and more frequent pollution events-implying MF experiences worse dust pollution. Although $\mathrm{TZ}$ is situated in the hinterland of the desert and has a sufficient dust source, the wind fields converge strongly and rise in the MF areas as the cold airstreams that flow from different directions intrude into the basin, resulting in a higher frequency of dust emission in $\mathrm{MF}[22,30]$. The $\mathrm{PM}_{10}, \mathrm{PM}_{2.5}$, and $\mathrm{PM}_{1.0}$ concentrations increased dramatically with the increase in the pollution level (Figure $4 \mathrm{~b}-\mathrm{d}$ ), especially the $\mathrm{PM}_{10}$ concentration (Figure $4 \mathrm{~b}$ ). In $\mathrm{MF}$, during the clear days, the $\mathrm{PM}_{10}, \mathrm{PM}_{2.5}$, and $\mathrm{PM}_{1.0}$ concentrations are 176.3, 37.5, and $12.1 \mu \mathrm{g} / \mathrm{m}^{3}$ respectively, and, under heavy pollution, their concentrations increase to 1287.6, 227.6, and $50.8 \mu \mathrm{g} / \mathrm{m}^{3}$, respectively. In TZ, during the clear days, the $\mathrm{PM}_{10}, \mathrm{PM}_{2.5}$, 
and $\mathrm{PM}_{1.0}$ concentrations are $144.0,36.2$, and $8.4 \mu \mathrm{g} / \mathrm{m}^{3}$, respectively, while during heavy pollution their concentrations increase to $1695.7,413.8$, and $81.5 \mu \mathrm{g} / \mathrm{m}^{3}$, respectively. By comparison, it is found that although the dust pollution frequency of TZ is less than that of $\mathrm{MF}$, the dust concentration of TZ is obviously larger than that of MF with the aggravation of pollution. This phenomenon may be attributed to the larger particle size in TZ than that of MF, since the smaller dust particles of MF can easily suspend in the air for a longer period, causing more frequent and worse dust pollution.

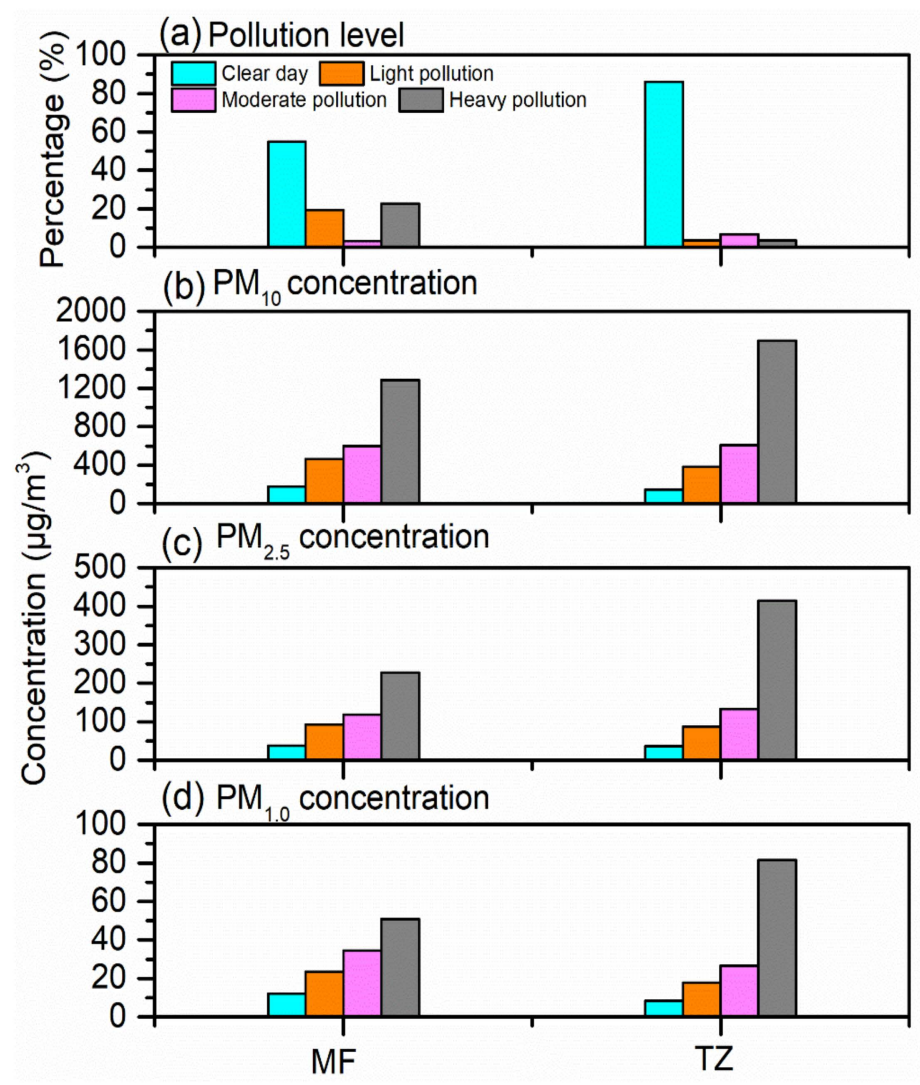

Figure 4. Comparison of the pollution level and concentration in MF and TZ during July 2021. (a) pollution level, (b) $\mathrm{PM}_{10}$, (c) $\mathrm{PM}_{2.5}$, (d) $\mathrm{PM}_{1.0}$.

\subsection{Vertical Structure of Dust with Different Particle Sizes Observed by UAV}

As we know, the vertical distribution of dust aerosols largely determines their horizontal and vertical motion [31], which has a decisive effect on the atmospheric thermal structure as well as the dust aerosol radiative forcing [8,9]. Figure 5 shows the vertical distributions of the particle concentrations with different sizes in MF and TZ during the observation period-the blank are the default values. It indicates that dust particles can be carried to high altitudes in MF and TZ with the occurrence of dust events (Figure 5c,f). Large discrepancies were observed in the vertical transport of dust particles between MF and TZ. In MF, the suspended dust particles are dominated by $\mathrm{PM}_{1.0}$ and $\mathrm{PM}_{2.5}$ (Figure 5a,b); in $\mathrm{TZ}$, although high concentrations of $\mathrm{PM}_{1.0}$ and $\mathrm{PM}_{2.5}$ are observed in suspended dust particles (Figure 5d,e), their concentrations are significantly lower than that of MF, especially $\mathrm{PM}_{1.0}$, which can hardly be detected. It suggests that larger particles are carried high in the hinterland of the TD (TZ), which is consistent with the results of Figure 4 . In order to further understand the vertical distribution of particle size, the concentration ratios of $\mathrm{PM}_{1.0} / \mathrm{PM}_{2.5}, \mathrm{PM}_{1.0} / \mathrm{PM}_{10}$, and $\mathrm{PM}_{2.5} / \mathrm{PM}_{10}$ are given in detail in the following. 
(a)
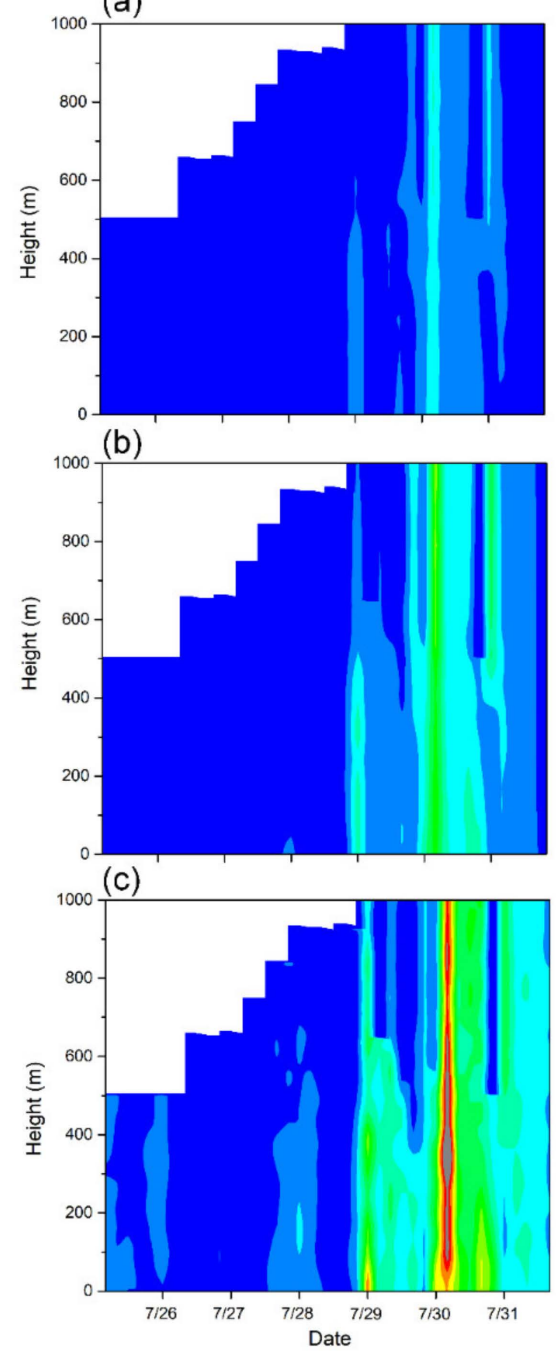

(d)

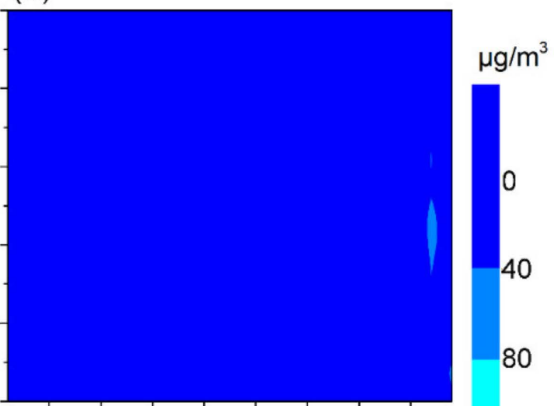

(e)

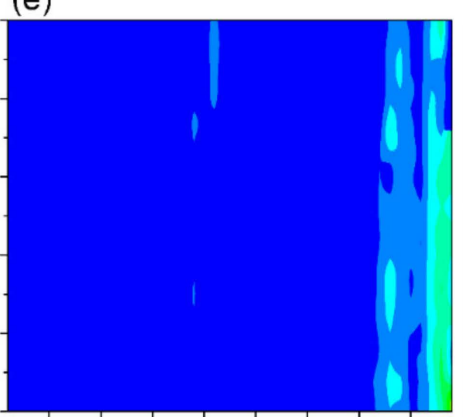

120

160

200

240

280

(f)

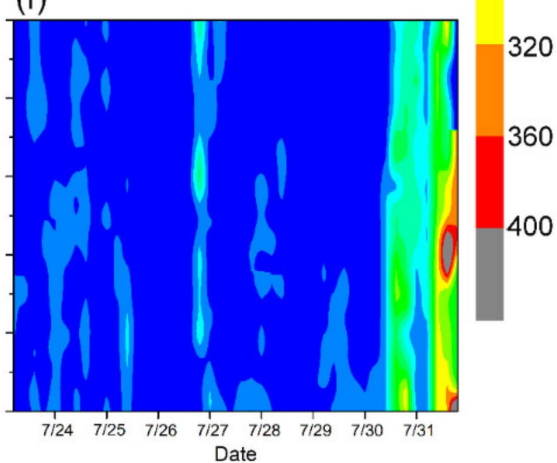

Figure 5. Vertical distributions of particle concentration with different sizes in $\mathrm{MF}\left((\mathbf{a}), \mathrm{PM}_{1.0}\right.$; (b), $\left.\mathrm{PM}_{2.5} ;(\mathbf{c}), \mathrm{PM}_{10}\right)$ and $\mathrm{TZ}\left((\mathbf{d}), \mathrm{PM}_{1.0} ;(\mathbf{e}), \mathrm{PM}_{2.5} ;(\mathbf{f}), \mathrm{PM}_{10}\right)$ during the observation period.

In MF, the detection height of the UAV was adjusted from $500 \mathrm{~m}$ to $1000 \mathrm{~m}$ at the later stage of observation. Therefore, in order to better compare the observation results, the height of MF was unified to $500 \mathrm{~m}$ (Figure 6). Figure 6a,b shows the comparison of the dust concentrations between clear days and pollution days in MF during the observation period, with pollution days indicating that the air quality level is greater than or equal to level 3. On clear days, the average $\mathrm{PM}_{1.0}, \mathrm{PM}_{2.5}$, and $\mathrm{PM}_{10}$ concentrations are 12.5, 29.0 , and $52.1 \mu \mathrm{g} / \mathrm{m}^{3}$, respectively, and are $58.2,113.8$, and $206.1 \mu \mathrm{g} / \mathrm{m}^{3}$ on dust pollution days, respectively. Figure $6 c, e$ shows the vertical distribution of $\mathrm{PM}_{1.0} / \mathrm{PM}_{2.5}, \mathrm{PM}_{1.0} / \mathrm{PM}_{10}$, and $\mathrm{PM}_{2.5} / \mathrm{PM}_{10}$. The average concentration ratios of $\mathrm{PM}_{1.0} / \mathrm{PM}_{2.5}, \mathrm{PM}_{1.0} / \mathrm{PM}_{10}$, and $\mathrm{PM}_{2.5} / \mathrm{PM}_{10}$ are 53.6, 29.9, and 55.8\% on clear days, respectively, and are 51.3, 28.4, and $55.4 \%$ on dust pollution days, respectively. In summary, with the occurrence of dust pollution, the concentration ratios of $\mathrm{PM}_{1.0} / \mathrm{PM}_{2.5}, \mathrm{PM}_{1.0} / \mathrm{PM}_{10}$, and $\mathrm{PM}_{2.5} / \mathrm{PM}_{10}$ are similar to those on clear days with a slight reduction. It is worth noting that with the occurrence of pollution, the ratio of $\mathrm{PM}_{2.5} / \mathrm{PM}_{10}$ is significantly larger than that on clear days between $0.080-0.315 \mathrm{~km}$ (Figure 6e). 

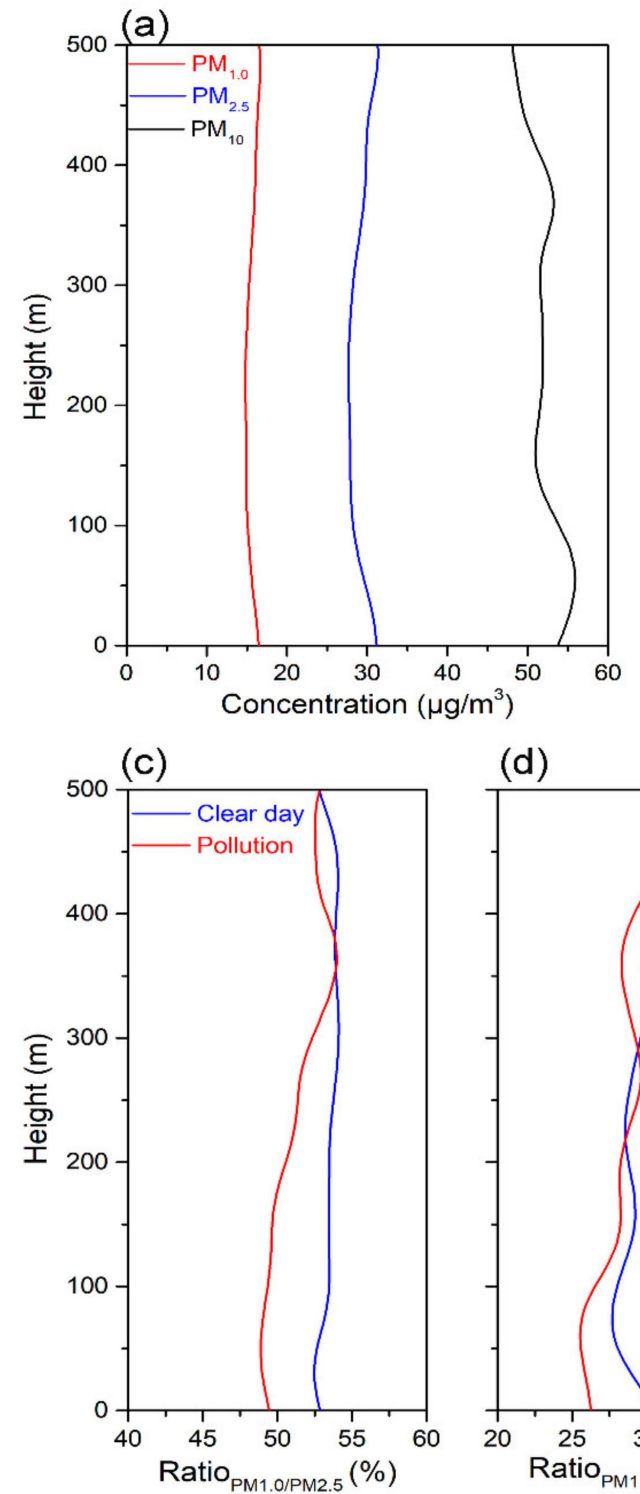

(d) (b)
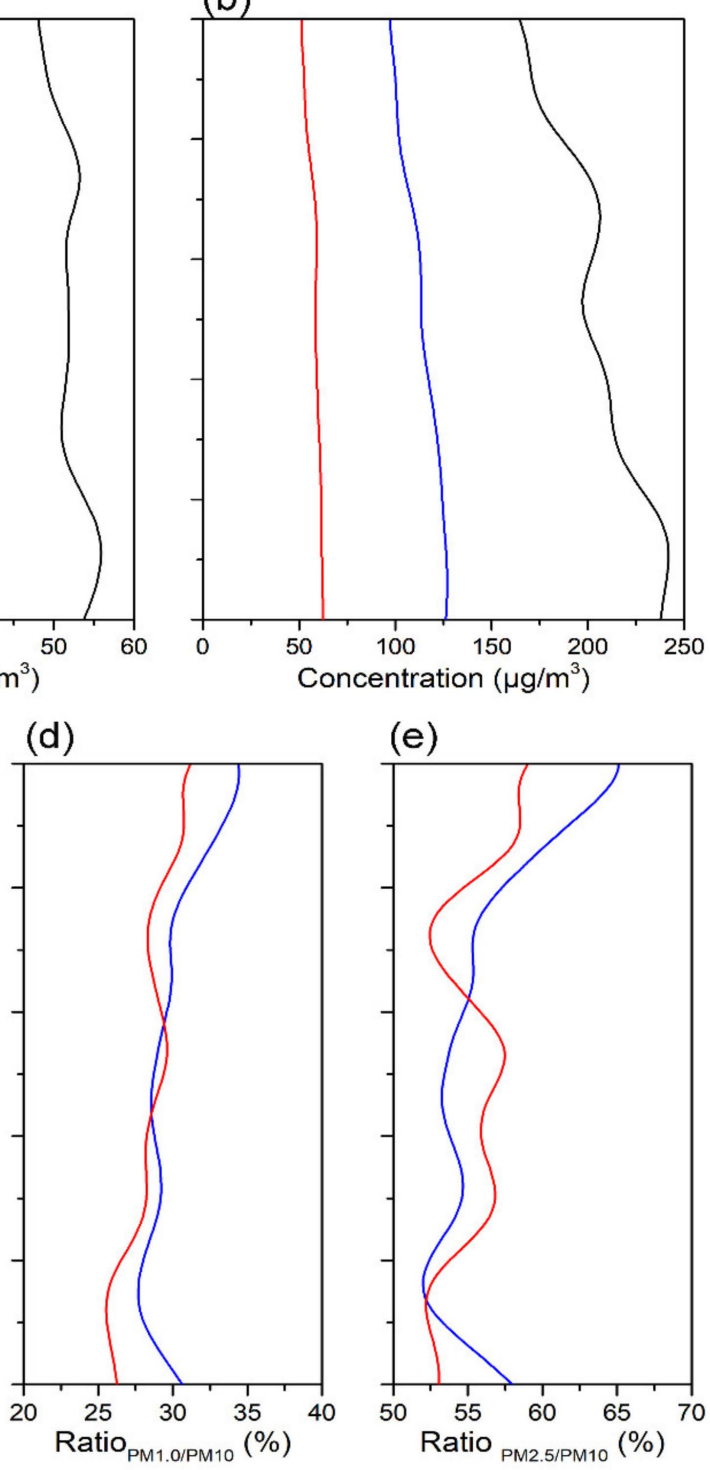

(e)

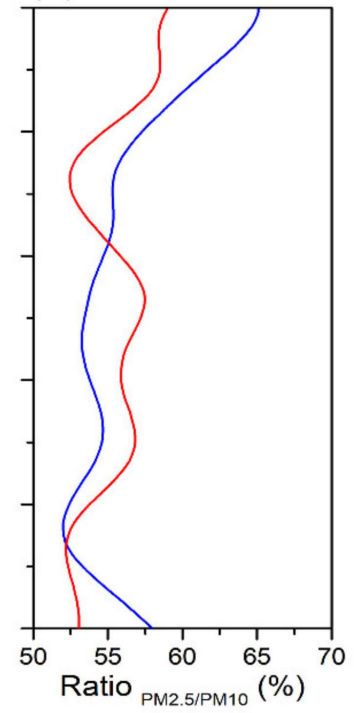

Figure 6. Comparison of the dust concentration between clear days (a) and pollution days (b); and the concentration ratio of (c) $\mathrm{PM}_{1.0} / \mathrm{PM}_{2.5}$, (d) $\mathrm{PM}_{1.0} / \mathrm{PM}_{10}$, (e) $\mathrm{PM}_{2.5} / \mathrm{PM}_{10}$ in $\mathrm{MF}$ during the observation period.

Figure 7 is the same as Figure 6, but for TZ. On clear days, the average $\mathrm{PM}_{1.0}, \mathrm{PM}_{2.5}$, and $\mathrm{PM}_{10}$ concentrations are $4.4,17.5$, and $33.8 \mu \mathrm{g} / \mathrm{m}^{3}$, respectively; the average concentration ratios of $\mathrm{PM}_{1.0} / \mathrm{PM}_{2.5}, \mathrm{PM}_{1.0} / \mathrm{PM}_{10}$, and $\mathrm{PM}_{2.5} / \mathrm{PM}_{10}$ are $25.3,13.1$, and 51.8\%, respectively. On dust pollution days, the average $\mathrm{PM}_{1.0}, \mathrm{PM}_{2.5}$, and $\mathrm{PM}_{10}$ concentrations reach $26.1,123.3$, and $279.5 \mu \mathrm{g} / \mathrm{m}^{3}$, respectively, and the average concentration ratios of $\mathrm{PM}_{1.0} / \mathrm{PM}_{2.5}, \mathrm{PM}_{1.0} / \mathrm{PM}_{10}$, and $\mathrm{PM}_{2.5} / \mathrm{PM}_{10}$ are $21.4,9.5$, and $44.9 \%$, respectively. Therefore, the concentration ratios of $\mathrm{PM}_{1.0} / \mathrm{PM}_{2.5}, \mathrm{PM}_{1.0} / \mathrm{PM}_{10}$, and $\mathrm{PM}_{2.5} / \mathrm{PM}_{10}$ decreased significantly in $\mathrm{TZ}$ with the occurrence of dust pollution. Figure $7 \mathrm{~d}$,e also shows that the concentration ratios of $\mathrm{PM}_{1.0} / \mathrm{PM}_{10}$ and $\mathrm{PM}_{2.5} / \mathrm{PM}_{10}$ decrease more obviously as height increases. 
(a)

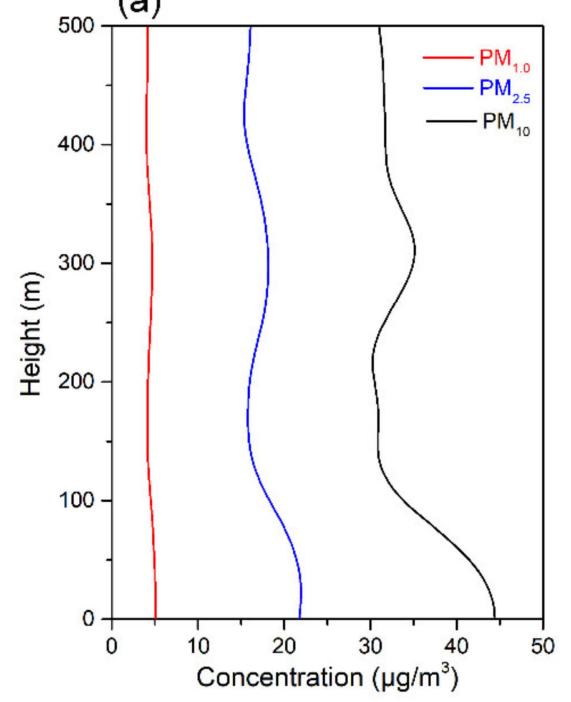

(c)

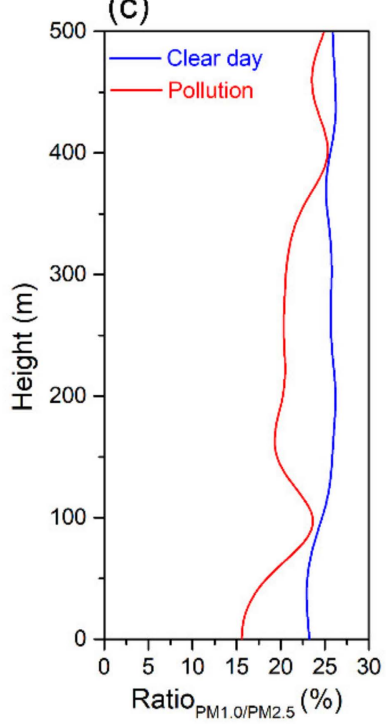

(b)

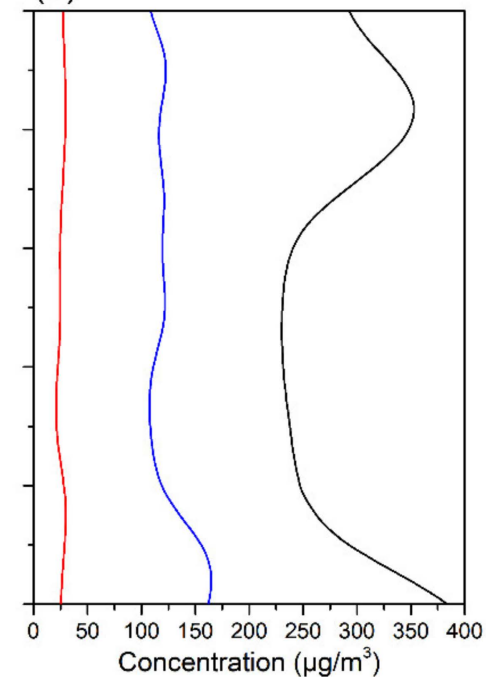

(e)
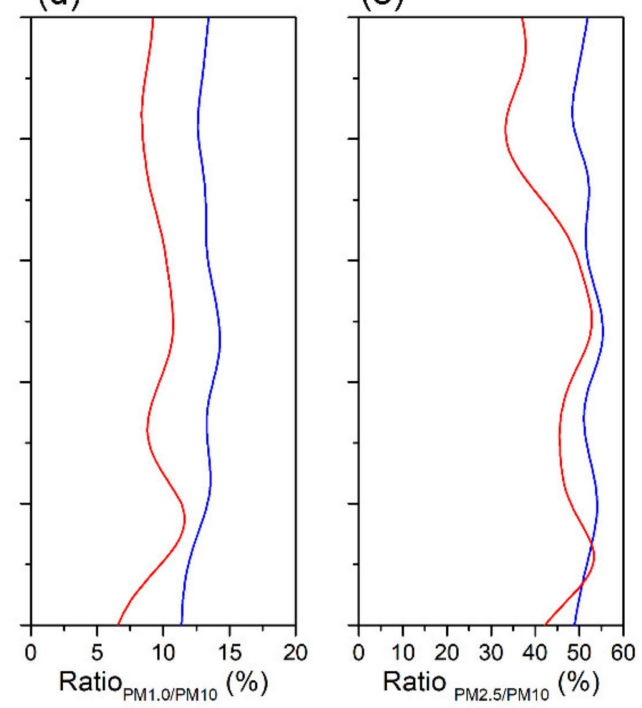

Figure 7. Comparison of the dust concentration between clear days (a) and pollution days (b); and the concentration ratio of (c) $\mathrm{PM}_{1.0} / \mathrm{PM}_{2.5}$, (d) $\mathrm{PM}_{1.0} / \mathrm{PM}_{10}$, (e) $\mathrm{PM}_{2.5} / \mathrm{PM}_{10}$ in $\mathrm{TZ}$ during the observation period.

\subsection{Dust Radiative Forcing and Atmospheric Boundary Layer Height over TD}

The results above illustrate the vertical distribution of dust concentrations and particle sizes in detail, which shows that the TD dust can suspend in the air with dust pollution. As an absorption aerosol, dust exerts a significant effect on the radiation budget of the land-atmosphere system and global/regional climate change [1-4]. Figure 8a-c shows the vertical distribution of the $\mathrm{PM}_{10}$ concentration and radiation at 14:00 on 30-31 July 2021 in $\mathrm{TZ}$, indicating that the increase in dust concentration is associated with the weakening of total solar radiation. The average total solar radiation was $969.6 \mathrm{~W} / \mathrm{m}^{2}$ on the clear days during the observation period, while it was $758.0 \mathrm{~W} / \mathrm{m}^{2}$ on 30 July (mean $\mathrm{PM}_{10}$ concentration was $115.9 \mu \mathrm{g} / \mathrm{m}^{3}$ ) and $550.3 \mathrm{~W} / \mathrm{m}^{2}$ on 31 July (mean $\mathrm{PM}_{10}$ concentration was $247.2 \mu \mathrm{g} / \mathrm{m}^{3}$ ). Meanwhile, during the dust polluted phase, temperature stratification was significantly modified (Figure 8d), which specifically presented low-level cooling (the mean temperature difference was $-1.78{ }^{\circ} \mathrm{C}$ on 30 July and $-3.63^{\circ} \mathrm{C}$ on 31 July) and high-level heating (the mean temperature difference was $+1.28{ }^{\circ} \mathrm{C}$ on 30 July and $+0.12{ }^{\circ} \mathrm{C}$ on 31 July). The heavier the dust concentration, the more obvious the cooling of the low-level and the higher cooling layer (the height of the cooling layer was $1080 \mathrm{~m}$ on 30 July and was $1730 \mathrm{~m}$ 
on 31 July). The warming intensity of the upper layer was smaller than the cooling intensity of the lower layer. This is mainly because the lower layer cooling somehow reflected the total effect of dust aerosol extinction, which contained both shortwave radiation absorption and scattering. However, the upper layer was only related to light absorption $[32,33]$.
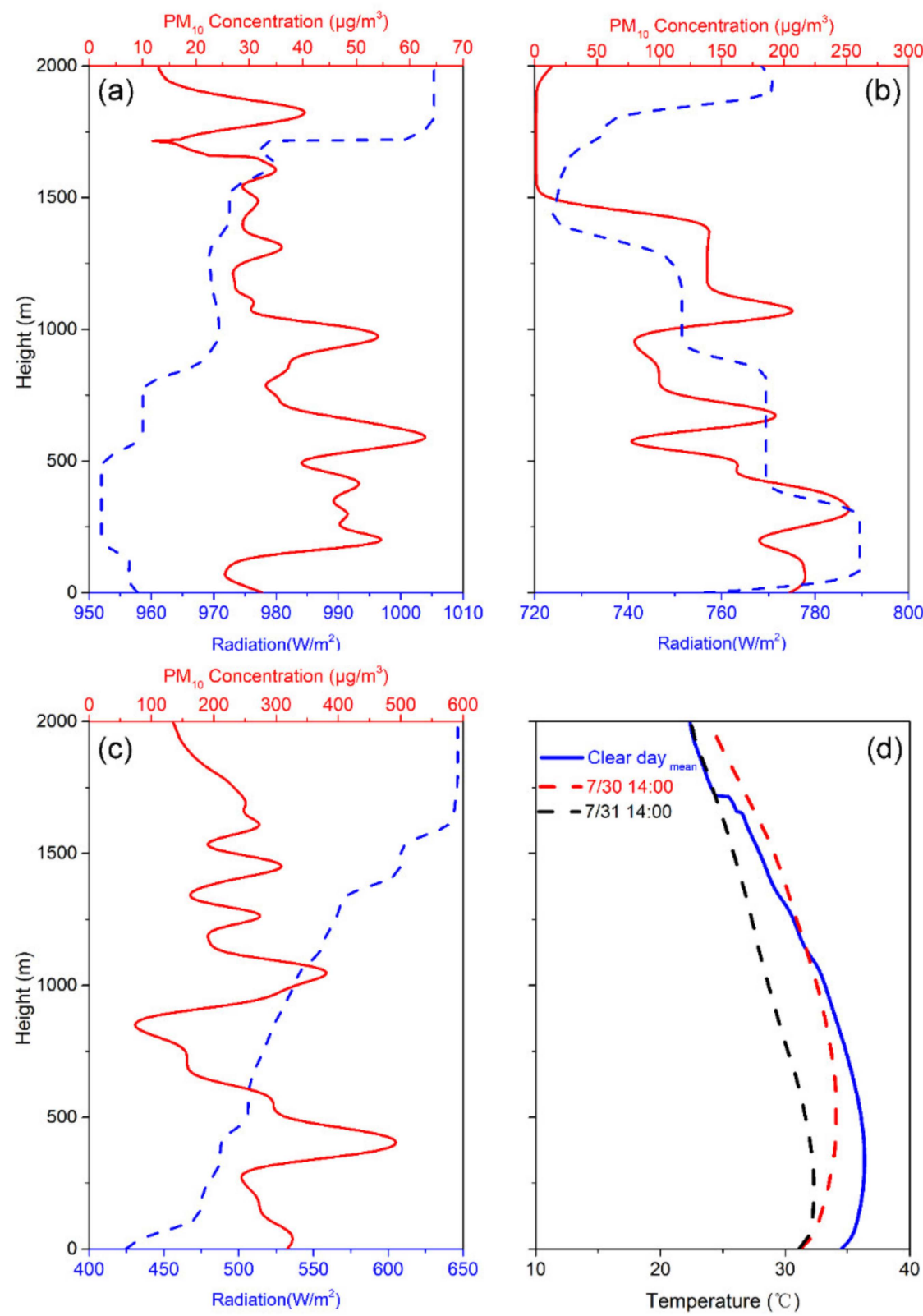

Figure 8. Vertical distribution of $\mathrm{PM}_{10}$ concentration, radiation, and temperature at 14:00 on 30-31 July 2021 in TZ, (a) mean of clear days; (b) 30 July 2021; (c) 31 July 2021; (d) temperature.

Normally, since the ABL sufficiently developed during the day and stabilized at night, the ABL height was measured at 14:00 (the convective boundary layer, CBL) and 02:00 (the stable boundary layer, SBL) [29]. The vertical distribution of the potential temperature under different pollution conditions during July 2021 in TZ and MF is shown in Figure 9. In $\mathrm{TZ}$, the average CBL heights during clear days, light dust pollution, moderate dust pollution, and heavy dust pollution were approximately $3.94,2.79,0.76$, and $0.72 \mathrm{~km}$, respectively, and the average SBL heights during clear days, light dust pollution, moderate dust pollution, and heavy dust pollution were approximately $0.19,0.23,0.27$, and $0.52 \mathrm{~km}$, respectively. In $\mathrm{MF}$, the average $\mathrm{CBL}$ heights during clear days, light dust pollution, moderate dust pollution, and heavy dust pollution were approximately 2.84, 1.38, 1.08, and 
$0.96 \mathrm{~km}$, respectively, and the average SBL heights during clear days, light dust pollution, moderate dust pollution, and heavy dust pollution were approximately $0.14,0.21,0.90$, and $1.03 \mathrm{~km}$, respectively. With the increasing dust pollution level, the CBL height decreases dramatically, which may be attributed to dust aerosol radiation effects and cloudy weather. By contrast, the change in SBL height shows the opposite trend, and the SBL height shows little difference between the dust pollution days and clear days compared with the CBL height. It is the suppression of CBL development that mainly promotes the dust suspension in the air. As a consequence, the unique ultra-high ABL structure provides beneficial conditions for the vertical transportation and suspension of dust in the air in TD.
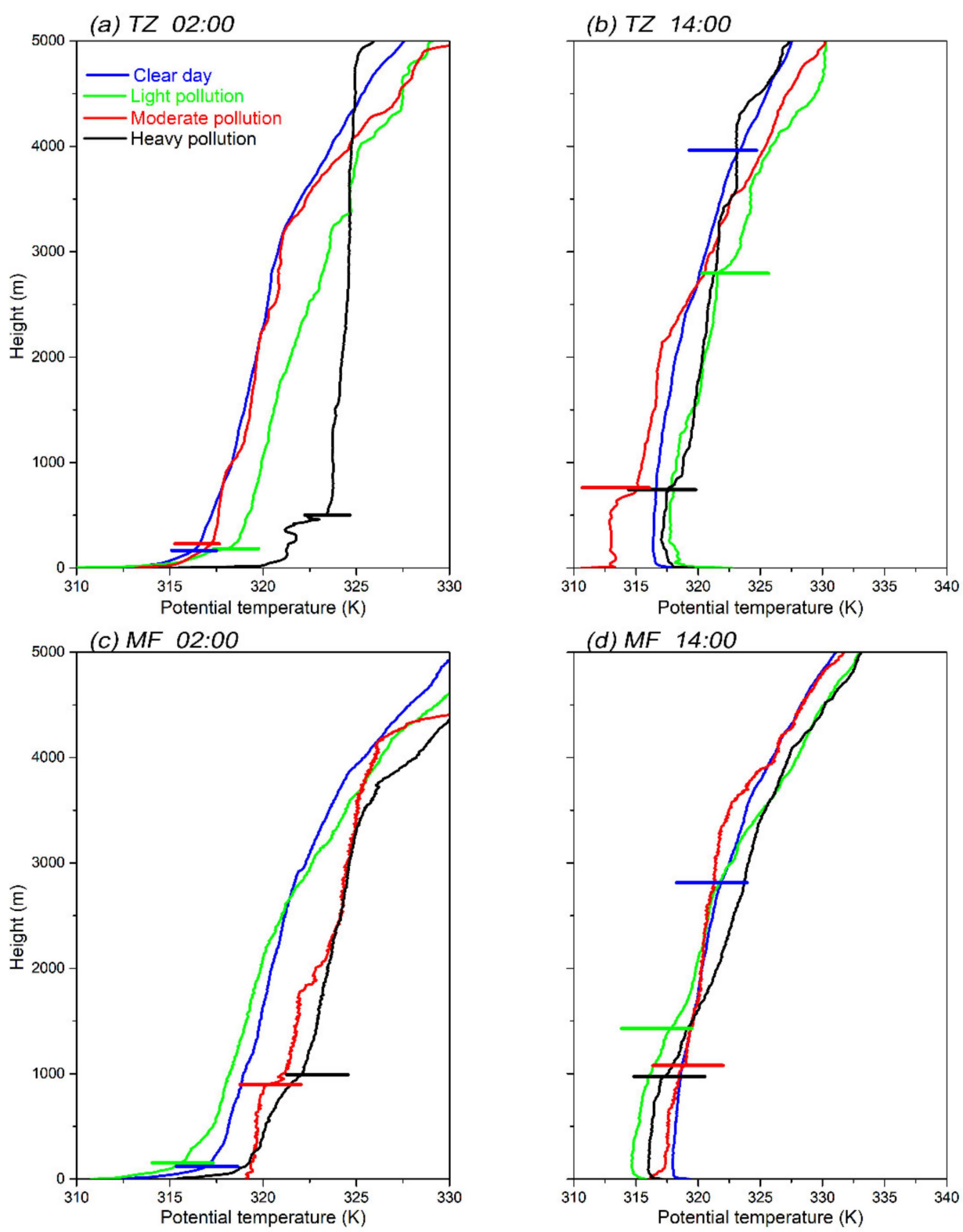

Figure 9. Vertical distribution of potential temperature under different pollution conditions during July 2021 in TZ and MF. (a) 02:00, TZ; (b) 14:00, TZ; (c) 02:00, MF; (d) 14:00, MF.

\section{Discussion}

The ABL height indicates the height where turbulence almost vanishes and is considered a key parameter in dust emission [34-37]. It has a close relationship with turbulent mixing and surface dust concentration. The ABL height is determined by the thermodynamic and dynamic effects of turbulent motion. The temporal variations of the CBL heights 
in MF and TZ during the observation period are shown in Figure 10a,b. The CBL height is much lower on dust pollution days, which is consistent with the previous study [29].

The relationships between the CBL height and the near-surface concentrations of $\mathrm{PM}_{10} / \mathrm{PM}_{2.5} / \mathrm{PM}_{1.0}$ in greater detail are shown in Figure $10 \mathrm{c}, \mathrm{d}$. In MF, there is a negative relationship between the $\mathrm{PM}_{10} / \mathrm{PM}_{2.5} / \mathrm{PM}_{1.0}$ concentrations and the $\mathrm{CBL}$ height throughout the entirety of July 2021, and their relationships were explored using power functions, with an $\mathrm{R}^{2}$ of 0.32 , 0.31 , and 0.27 for $\mathrm{PM}_{10} / \mathrm{PM}_{2.5} / \mathrm{PM}_{1.0}$ concentration, respectively (Figure $10 \mathrm{c}$ ). The relationship in TZ is similar to that in MF, but with the higher $\mathrm{R}^{2}$ of $0.46,0.53$, and 0.51 for $\mathrm{PM}_{10} / \mathrm{PM}_{2.5} / \mathrm{PM}_{1.0}$ concentration, respectively. (Figure 10d). In summary, the negative relationship between the surface PM concentration and the CBL is presented, but it is not suitable for the SBL. It indicates that the relationship between the PM concentration near-surface and the SBL is more complicated [24].

Surface cooling at night will lead to the cooling of the boundary layer from bottom to top, forming an SBL with an inverse potential temperature stratification. In fact, it is very difficult to study the SBL. Firstly, the turbulent energy in the SBL is very weak and the turbulent exchange is not dominant compared with other heat exchange processes; then, various parameters have no obvious transition characteristics at the top of the boundary layer, hence, it is difficult to determine the position of the top layer. Of course, the weak turbulence makes it difficult to separate their value characteristics from the observation error. Fortunately, various processes in the boundary layer change weakly with time as the SBL develops to the middle and late stages and the SBL can be regarded as steady. Therefore, the relationship between the SBL and surface PM concentration needs further discussion.
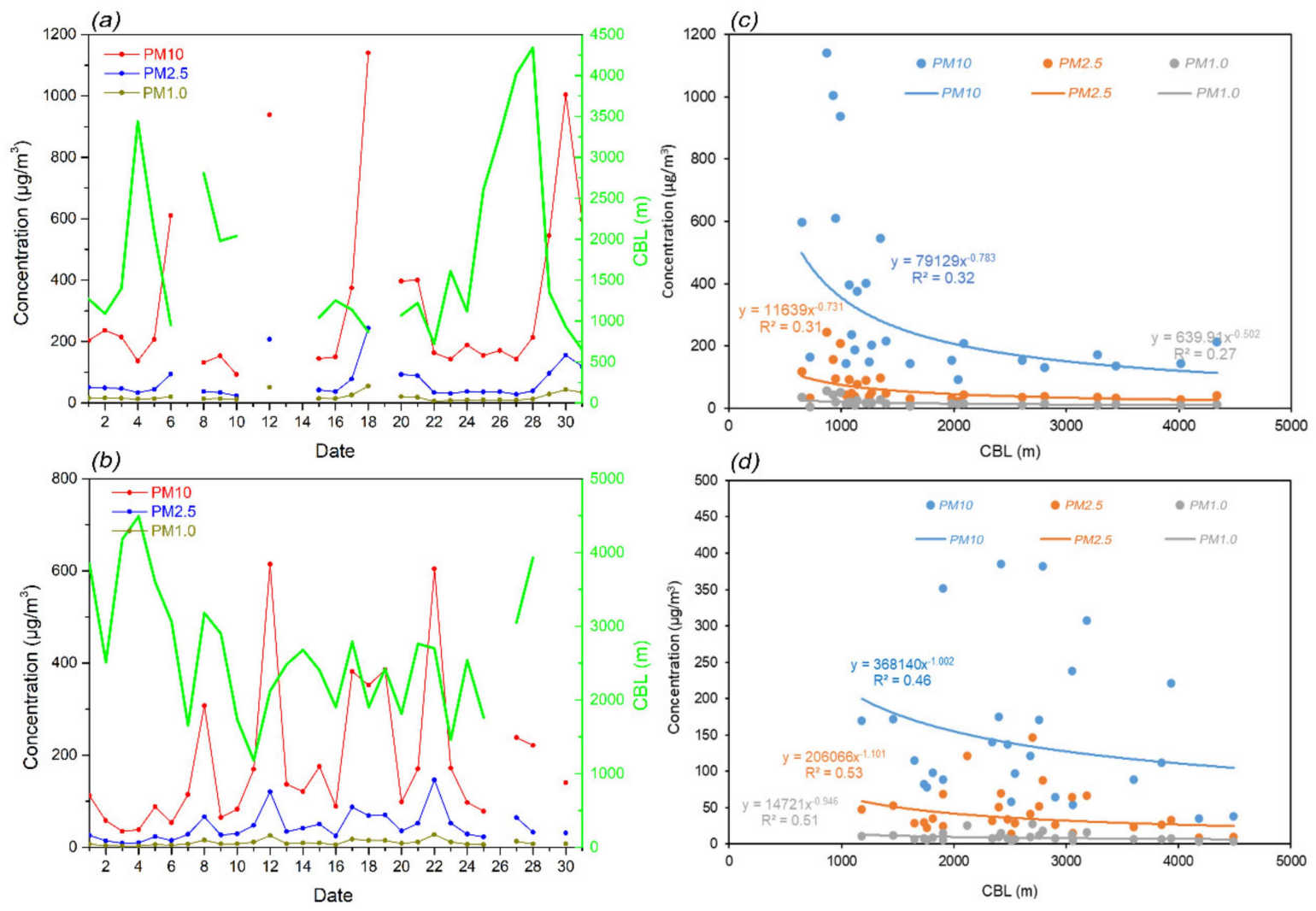

Figure 10. Temporal variations of $\mathrm{PM}_{10} / \mathrm{PM}_{2.5} / \mathrm{PM}_{1.0}$ concentrations in the surface layer, and the ABLH in MF (a) and TZ (b); the relationships between PM concentration near-surface and ABLH in MF (c) and TZ (d). 


\section{Conclusions}

Based on multi-source comprehensive intensive observation experiments carried out from 1 to 31 July 2021 in TD, the vertical structure of dust with different particle sizes was investigated.

The power functions are fitted and show a negative correlation between the particle counts and particle sizes, with an $\mathrm{R}^{2}$ higher than 0.99 under different dust pollution levels. The counts of particles increase rapidly with the aggravation of dust pollution; however, particle counts decrease at a slower rate under larger particle sizes. When the particle size is larger than $10 \mu \mathrm{m}$, the particle counts reduce to near-zero.

Under dust pollution conditions, the vertical dust concentration increases sharply over the TD. In MF, the average concentration ratios of $\mathrm{PM}_{1.0} / \mathrm{PM}_{2.5}, \mathrm{PM}_{1.0} / \mathrm{PM}_{10}$, and $\mathrm{PM}_{2.5} / \mathrm{PM}_{10}$ are 53.6, 29.9, and 55.8\% on clear days, respectively, and are 51.3, 28.4, and $55.4 \%$ on dust pollution days, respectively. By contrast, in $\mathrm{TZ}$, the average concentration ratios of $\mathrm{PM}_{1.0} / \mathrm{PM}_{2.5}, \mathrm{PM}_{1.0} / \mathrm{PM}_{10}$, and $\mathrm{PM}_{2.5} / \mathrm{PM}_{10}$ are $25.3,13.1$, and $51.8 \%$ on clear days, respectively, and are $21.4,9.5$, and $44.9 \%$ on dust pollution days, respectively. The results indicate that more particles with larger sizes are entrained into the air in TZ during dusty days.

During dust pollution days, the total solar radiation is much smaller than that during clear days. Correspondingly, the temperature stratification was significantly modified, which presented low-level cooling (the mean temperature difference was $-1.78{ }^{\circ} \mathrm{C}$ on 30 July and $-3.63{ }^{\circ} \mathrm{C}$ on 31 July) and high-level heating (the mean temperature difference was $+1.28^{\circ} \mathrm{C}$ on 30 July and $+0.12{ }^{\circ} \mathrm{C}$ on 31 July).

The average CBL heights during clear days, light dust pollution, moderate dust pollution, and heavy dust pollution were approximately $3.94,2.79,0.76$, and $0.72 \mathrm{~km}$ in TZ, respectively, and were approximately $2.84,1.38,1.08$, and $0.96 \mathrm{~km}$ in MF, respectively.

The average SBL heights during clear days, light dust pollution, moderate dust pollution, and heavy dust pollution were approximately $0.19,0.23,0.27$, and $0.52 \mathrm{~km}$ in TZ, respectively, and were approximately $0.14,0.21,0.90$, and $1.03 \mathrm{~km}$ in MF, respectively. The CBL height decreases rapidly; however, the SBL height shows the opposite trend with the increasing dust pollution level.

Finally, the relationship between the CBLH and surface PM concentration was discussed. In MF, the relationship can be described as a power function with an $\mathrm{R}^{2}$ of 0.32 , 0.31 , and 0.27 for the surface $\mathrm{PM}_{10} / \mathrm{PM}_{2.5} / \mathrm{PM}_{1.0}$ concentrations, respectively. The situation in TZ is similar to that of MF, but with an $\mathrm{R}^{2}$ of $0.46,0.53$, and 0.51 for the surface $\mathrm{PM}_{10} / \mathrm{PM}_{2.5} / \mathrm{PM}_{1.0}$ concentrations, respectively.

Author Contributions: Y.L. conceptualization; writing-reviewing and editing. C.Z. writing-original draft preparation with contributions from the coauthors. Q.H., X.Z., Q.Z., F.Y., W.H., A.M., X.Y., Y.W. and L.M. carried out the experiment, data curation and supervision. All authors have read and agreed to the published version of the manuscript.

Funding: This research was supported by National Natural Science Foundation of China (42030612, 41905009) and jointly supported by the Strategic Priority Research Program of the Chinese Academy of Sciences (Grant No. XDA2006010301), the Xinjiang Natural Science Founds of China (2021D01A197), the Basic Business Expenses (IDM2021001), National Natural Science Foundation of China (41975010, 41875019), the Fundamental Research Funds for the Central Universities (lzujbky-2020-kb02) and the Flexible Talents Introducing Project of Xinjiang (2018).

Data Availability Statement: Institute of Desert Meteorology, China Meteorological Administration (IDM) supplied the observation data used to support the findings of this study by the under license, therefore, they cannot be made freely available.

Acknowledgments: We thank Institute of Atmospheric Physics, Chinese Academy of Sciences and Hangzhou Zog communication equipment Co., Ltd. for their help in this field experiment.

Conflicts of Interest: The authors declare no conflict of interest. 


\section{References}

1. Jia, R.; Liu, Y.; Hua, S.; Zhu, Q.; Shao, T. Estimation of the aerosol radiative effect over the Tibetan Plateau based on the latest CALIPSO product. J. Meteorol. Res. 2018, 32, 707-722. [CrossRef]

2. Liu, Y.; Jia, R.; Dai, T.; Xie, Y.; Shi, G. A review of aerosol optical properties and radiative effects. J. Meteorol. Res. 2014, 8, 1003-1028. [CrossRef]

3. Huang, J.; Fu, Q.; Su, J.; Tang, Q.; Minnis, P.; Hu, Y.; Yi, Y.; Zhao, Q. Taklimakan dust aerosol radiative heating derived from CALIPSO observations using the Fu-Liou radiation model with CERES constraints. Atmos. Chem. Phys. 2009, 9, $4011-4021$. [CrossRef]

4. Chen, S.; Huang, J.; Li, J.; Jia, R.; Jiang, N.; Kang, L.; Ma, X.; Xie, T. Comparison of dust emission, transport, and deposition between the Taklimakan Desert and Gobi Desert from 2007 to 2011. Sci. China Earth Sci. 2017, 60, 1338-1355. [CrossRef]

5. Gong, S.L.; Zhang, X.Y.; Zhao, T.L.; Mckendry, I.G.; Jaffe, D.A.; Lu, N.M. Characterization of soil dust aerosol in China and its transport and distribution during 2001 ACE-Asia: 2. model simulation and validation. J. Geophys. Res. 2003, 108, D9. [CrossRef]

6. Zhou, C.; Yang, F.; Mamtimin, A.; Huo, W.; Liu, X.; He, Q.; Zhang, J.; Yang, X. Wind erosion events at different wind speed levels in the Tarim Basin. Geomorphology 2020, 369, 107386. [CrossRef]

7. Huang, J.P.; Wang, T.H.; Wang, W.C.; Li, Z.; Yan, H. Climate effects of dust aerosols over East Asian arid and semiarid regions. J. Geophy. Res. 2014, 119, 11398-11416. [CrossRef]

8. Claquin, T.; Schulz, M.; Balkanski, Y.; Boucher, O. Uncertainties in assessing radiative forcing by mineral dust. Tellus B 1998, 50, 491-505. [CrossRef]

9. Zhang, G.; Zhang, Z.; Liu, J. Spatial distribution of wind erosion and its driving factors in China. J. Geogr. Sci. 2001, 11, 127-139.

10. Xu, X.; Zhou, X.; Weng, Y.; Tian, G.; Liu, Y.; Yan, P.; Ding, G.; Zhang, Y.; Mao, J.; Qiu, H. Study on variational aerosol fields over Beijing and its adjoining areas derived from Terra-MODIS and ground sunphotometer observation. Chin. Sci. Bull. 2003, 48, 2010-2017. [CrossRef]

11. Qiu, H.; Zhong, J.; Dong, X. Land-use and land-cover changes and dust storms in Tarim Basin, northwest China. Proc. SPIE Int. Soc. Opt. Eng. 2003, 4890, 652-656.

12. Huang, L.; Jiang, J.; Tackett, J.; Su, H.; Fu, R. Seasonal and diurnal variations of aerosol extinction profile and type distribution from CALIPSO 5-year observations. J. Geophys. Res. Atmos. 2013, 118, 4572-4596. [CrossRef]

13. Guo, J.; Liu, H.; Wang, F.; Huang, J.; Xia, F.; Lou, M.; Wu, Y.; Jiang, J.; Xie, T.; Zhaxi, Y.; et al. Three-dimensional structure of aerosol in china: A perspective from multi-satellite observations. Atmos. Res. 2016, 178, 580-589. [CrossRef]

14. Liu, D.; Zhao, T.L.; Richard, B.; Chen, S.Y.; Lu, Z.Q.; Wu, Y.; Zhao, Y. Vertical Structures of Dust Aerosols over East Asia Based on CALIPSO Retrievals. Remote Sens. 2019, 11, 701. [CrossRef]

15. Alfaro, S.C.; Gaudichet, A.; Gomes, L.; Maille, M. Mineral aerosol production by wind ' erosion: Aerosol particle sizes and binding energies. Geophys. Res. Lett. 1998, 25, 991-994. [CrossRef]

16. Zhou, C.; Yang, F.; Huo, W.; Mamtimin, A.; Yang, X.-H. Size distribution of PM20 observed to the north of the Tibetan Plateau. J. Mt. Sci. 2021, 18, 367-376. [CrossRef]

17. Adebiyi, A.A.; Kok, J.F. Climate models miss most of the coarse dust in the atmosphere. Sci. Adv. 2020, 6, 9507. [CrossRef] [PubMed]

18. Di Biagio, C.; Balkanski, Y.; Albani, S.; Boucher, O.; Formenti, P. Direct radiative effect by mineral dust aerosols constrained by new microphysical and spectral optical data. Geophys. Res. Lett. 2020, 47, e2019GL086186. [CrossRef]

19. Kok, J.F.; Ridley, D.A.; Zhou, Q.; Miller, R.L.; Zhao, C.; Heald, C.L.; Ward, D.S.; Albani, S.; Haustein, K. Smaller desert dust cooling effect estimated from analysis of dust size and abundance. Nat. Geosci. 2017, 10, 274-278. [CrossRef]

20. Song, Q.; Zhang, Z.; Yu, H.; Kato, S.; Yang, P.; Colarco, P.; Remer, L.A.; Ryder, C.L. Net radiative effects of dust in the tropical North Atlantic based on integrated satellite observations and in situ measurements. Atmos. Chem. Phys. 2018, 18, 11303-11322. [CrossRef]

21. Zhou, C.L.; Ali, M.; Yang, F.; Huo, W.; Wang, M.Z.; Pan, H.L.; He, Q.; Jin, L.L.; Yang, X.H. Evaluation of wind erosion in the Tarim Basin based on parameter localization. Theor. Appl. Climatol. 2020, 140, 1071-1080. [CrossRef]

22. Han, Y.X.; Fang, X.M.; Song, L.C.; Zhang, Q.; Yang, S.L. A Study of Atmospheric Circulation and Dust Storm Causes of Formation in the Tarim Basin-The Restructured Wind Field by Shapes of Dune and Observed Prevailing Wind. J. Atmos. Sci. 2005, 29, 627-635. (In Chinese)

23. Li, X.L.; Wang, Y.F.; Shen, L.D.; Zhang, H.S.; Zhao, H.J.; Zhang, Y.H.; Ma, Y.J. Characteristics of boundary layer structure during a persistent haze event in the central Liaoning city cluster, Northeast China. J. Meteorol. Res. 2018, 32, 302-312. [CrossRef]

24. Li, Q.H.; Wu, B.G.; Liu, J.L.; Zhang, H.S.; Cai, X.H.; Song, Y. Characteristics of the atmospheric boundary layer and its relation with $\mathrm{PM}_{2.5}$ during haze episodes in winter in the North China Plain. Atmos. Environ. 2020, 223, 117265. [CrossRef]

25. Zhou, C.; He, Q.; Huo, W.; Yang, F.; Ali, M.; Pan, H.; Yang, X. Comparison of approaches for calculating the threshold velocity for sand movement based on field experiments in Xinjiang, China. Arab. J Geosci. 2018, 11, 402. [CrossRef]

26. Yang, Z.; Qian, G.; Han, Z.; Dong, Z.; Luo, W.; Zhang, Z.; Lu, J.; Liang, A.; Tian, M. Variation in grain-size characteristics as a function of wind direction and height in the Sanlongsha dune field of the northern Kumtagh Desert, China. Aeolian Res. 2019, 40, 53-64. [CrossRef]

27. Livingstone, I. Grain-size variation on a 'complex' linear dune in the Namib Desert. In Desert Sediments: Ancient and Modern; Frostick, L.E., Reid, I., Eds.; Geological Society of London Special Publication: London, UK, 1987; pp. $281-291$. 
28. Wang, X.; Dong, Z.; Zhang, J.; Qu, J.; Zhao, A. Grain size characteristics of dune sands in the central Taklimakan Sand Sea. Sediment. Geol. 2003, 161, 1-14. [CrossRef]

29. Li, Q.; Zhang, H.; Cai, X.; Song, Y.; Zhu, T. The impacts of the atmospheric boundary layer on regional haze in North China. NPJ-Clim. Atmos. Sci. 2021, 4, 9. [CrossRef]

30. Yang, F.; Huang, J.; Zhou, C.; Yang, X.; Ali, M.; Li, C.; Pan, H.; Huo, W.; Yu, H.; Liu, X.; et al. Taklimakan desert carbon-sink decreases under climate change. Sci. Bull. 2020, 65, 431-433. [CrossRef]

31. Bourgeois, Q.; Ekman, A.; Krejci, R. Aerosol transport over the Andes from the Amazon Basin to the remote Pacific Ocean: A multiyear CALIOP assessment. J. Geophys. Res. Atmos. 2015, 120, 8411-8425. [CrossRef]

32. Ding, A.J.; Huang, X.; Nie, W.; Sun, J.N.; Kerminen, V.M.; Petäjä, T.; Su, H.; Cheng, Y.F.; Yang, X.Q.; Wang, M.H.; et al. Enhanced haze pollution by black carbon in megacities in China. Geophys. Res. Lett. 2016, 43, 2873-2879. [CrossRef]

33. Huang, X.; Wang, Z.L.; Ding, A.J. 2018. Impact of aerosol-PBL interaction on haze pollution: Multiyear observational evidences in North China. Geophys. Res. Lett. 2018, 45, 8596-8603. [CrossRef]

34. Zhang, H.; Zhang, X.; Li, Q.; Cai, X.; Fan, S.; Song, Y.; Hu, F.; Che, H.; Quan, J.; Kang, L. Research progress on estimation of the atmospheric boundary layer height. J. Meteorol. Res. 2020, 34, 482-498. [CrossRef]

35. Garratt, J.R. Review: The atmospheric boundary layer. Earth Sci. Rev. 1994, 37, 1-2, discussion 89-134. [CrossRef]

36. Stull, R.B. An Introduction to Boundary Layer Meteorology; Kluwer Academic Publishers: Amsterdam, The Netherlands, 1988.

37. Li, X.L.; Hu, X.M.; Ma, Y.J.; Wang, Y.F.; Li, L.G.; Zhao, Z.Q. Impact of planetary boundary layer structure on the formation and evolution of air-pollution episodes in Shenyang, Northeast China. Atmos. Environ. 2019, 214, 116850. [CrossRef] 